\title{
Bond behaviour of thin concrete overlays for maintenance of concrete pavements
}

\author{
Rolf Breitenbücher ${ }^{1, *}$, Christoph Schulte-Schrepping ${ }^{1}$, and Sebastian Kunz ${ }^{1}$ \\ ${ }^{1}$ Institute of Building Materials, Ruhr-University Bochum, 44801 Bochum, Germany
}

\begin{abstract}
Concrete pavements are exposed to a number of stresses during their service life, mostly resulting from traffic and climate conditions. In consideration of the continuously rising traffic volume, the durability requirements of concrete pavements become more and more significant. In this context, maintenance and repair become increasingly important. Small-scale repairs like spalling at edges up to the replacement of whole slabs are proven in several cases. In contrast, largescale maintenance techniques for partial repairs of whole pavement sections are not available, yet. If the upper layer concrete is deteriorated, while the lower layer and the base course are still intact, the whole pavement needs to be replaced, due to a lack of alternatives. Therefore new maintenance techniques like the application of concrete overlays are needed for an economic rehabilitation and the prevention of an unnecessarily long traffic disruption by time-consuming maintenance of complete pavements. The relevant questions how a durable bond between old and new concrete can be ensured and which parameters affect this bond, were investigated in representative studies on large-scale concrete beams with a thin concrete overlay on existing concrete.
\end{abstract}

\section{Introduction}

Concrete pavements are exposed to a number of stresses during their service life, mostly resulting from traffic and climate conditions. Considering the continuously increasing traffic the durability requirement of concrete pavements becomes more and more significant. At the same time, the surface properties concerning texture and noise reduction have to be fulfilled.

In this context, maintenance and repair of concrete pavements become more and more important. Thereby, a main aim is to find economical and efficient construction methods to minimize life cycle costs without affecting the functionality and quality of concrete pavements.

Usually, maintenance of concrete pavements is conducted through the complete renewal of the deteriorated pavement. An alternative method to a replacement of the entire concrete structure is the targeted renewal of the upper part of the existing pavement, which is impaired (Figure 1) [1]. Therefore, the old concrete can be milled off and thus remains as base-course-layer.

\section{Bonded Concrete Overlays of Concrete Pavements} -previously called bonded overlays-

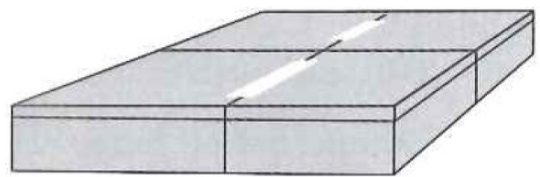

Fig. 1. Example for a bonded concrete overlay system [1]
In case of the so-called "Whitetopping" - by now a proven maintenance of asphalt pavements - a thin concrete layer, usually a fiber-reinforced, low-shrinkage high performance concrete is applied to an existing asphalt pavement (Figure 2).

For conventional Whitetopping concrete, paving thickness amounts to 200 to $260 \mathrm{~mm}$. For ThinWhitetopping (TWT) an overlay of more than $100 \mathrm{~mm}$ and less than $200 \mathrm{~mm}$ is commonly used. The thickness of Ultra-Thin Whitetopping (UTW) is usually equal to or less than $100 \mathrm{~mm}[1-6]$.

\section{Bonded Concrete Overlays of Asphalt Pavements -previously called ultra-thin whitetopping-}

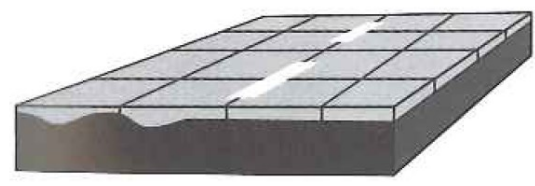

Fig. 2. Ultra-thin Whitetopping - bonded overlay system [1]

The maintenance of concrete pavements with a thin layer of new concrete is a relatively new field of work. In this context, the upper part of the existing pavement, which is impaired, is removed and will be replaced by a thin layer of new concrete. The crucial factor here is the bonding behaviour between the lower layer (old concrete) and the thin layer of new concrete, which largely depends on the mechanical and rheological

\footnotetext{
* Corresponding author: rolf.breitenbuecher@rub.de
} 
properties of both concretes as well as the surface conditions and roughness of the structural joint.

The objective of this study at the Institute of Building Materials (Ruhr-University Bochum, Germany) was to investigate the influence of cyclic loading and partial freeze-thaw-attack with de-icing agents on the bond properties of such concrete layers. Herein, a number of parameters are varied, including the moisture condition of the old concrete, the application of an adhesion primer, the consistency of the new concrete etc.. Within this paper the experimental investigations and an extract of the obtained results are presented.

\section{Experimental procedure}

\subsection{Parameter variation and test program}

Within this research work, large concrete beams with dimensions of $180 \times 50 \times 27 \mathrm{~cm}^{3}$, consisting of a lower layer (old concrete, thickness approx. $20 \mathrm{~cm}$ ) and a thin top layer (new concrete, thickness approx. $7 \mathrm{~cm}$ ) were investigated. The variations of the large concrete specimens are shown in Table 1.

Table 1. Test program

\begin{tabular}{|c|c|c|c|c|c|c|c|}
\hline \multirow{3}{*}{\multicolumn{2}{|c|}{ specimen }} & \multicolumn{2}{|c|}{$\begin{array}{c}\text { Moisture } \\
\text { condition of } \\
\text { joint }\end{array}$} & \multicolumn{4}{|c|}{ New concrete } \\
\hline & & \multirow{2}{*}{ dry } & \multirow{2}{*}{ moist } & \multicolumn{2}{|c|}{$\begin{array}{c}\text { Concrete } \\
\text { composition }\end{array}$} & \multicolumn{2}{|c|}{ consistency } \\
\hline & & & & M1 & M2 & stiff & soft \\
\hline \multirow{6}{*}{ 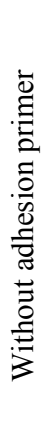 } & VB-1 & & $x$ & $\mathrm{x}$ & & & $\mathrm{x}$ \\
\hline & VB-2 & $\mathrm{x}$ & & $\mathrm{x}$ & & & $\mathrm{x}$ \\
\hline & VB-3 & & $\mathrm{x}$ & & $\mathrm{x}$ & & $\mathrm{x}$ \\
\hline & VB-4 & & $x$ & & $x$ & $x$ & \\
\hline & VB-6 & $\mathrm{x}$ & & & $\mathrm{x}$ & & $\mathrm{x}$ \\
\hline & VB-7 & & $\mathrm{x}$ & & $\mathrm{x}$ & & $\mathrm{x}$ \\
\hline \multirow{4}{*}{ 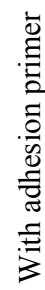 } & $\mathrm{H}-1$ & & $\mathrm{x}$ & $\mathrm{x}$ & & $\mathrm{x}$ & \\
\hline & $\mathrm{H}-2$ & & $\mathrm{x}$ & & $\mathrm{x}$ & $\mathrm{x}$ & \\
\hline & H-3 & $\mathrm{x}$ & & & $\mathrm{x}$ & $\mathrm{x}$ & \\
\hline & H-5 & & $x$ & & $\mathrm{x}$ & $\mathrm{x}$ & \\
\hline
\end{tabular}

The compressive strength of the old concrete generally amounted to approximately $60 \mathrm{MPa}$ with exception of VB-7, which amounted to $80 \mathrm{MPa}$. Furthermore, the moisture condition of the bond area (structural joint) was varied by producing a dry or moist surface. The mix design of the new concrete was varied by adding shrinkage reducing agents (SRA) (mix design
M2) to a conventional exposed aggregate concrete (mix design M1). In addition, the consistency was adjusted as very soft, specifically to a flow spread from 49 to $55 \mathrm{~cm}$ by an appropriate dosage of superplasticizer. In case of the large concrete beams H-1 to H-5, polymer modified adhesion primer was used. For that matter, all new concretes were produced with a stiff consistency and using a shrinkage reducing agent with the exception of $\mathrm{H}-1$, which was produced without SRA. The exposure time of the adhesive primer after application was generally about 20 to 30 minutes. Only for H-5 the exposure time was set to 2 hours. The application of the adhesion primer was conducted at an ambient temperature of approx. $20^{\circ} \mathrm{C}$.

\subsection{Concrete mix design}

Two characteristic concretes complying the requirements of the German guideline TL Beton-StB 07 [7] were used (Table 2).

Table 2. Mix designs for old and new concrete

\begin{tabular}{|l|l|c|c|}
\hline \multicolumn{2}{|l|}{} & $\begin{array}{c}\text { old } \\
\text { concrete }\end{array}$ & $\begin{array}{c}\text { new concrete } \\
\text { (M1/M2) }\end{array}$ \\
\hline cement & $\mathrm{kg} / \mathrm{m}^{3}$ & 360 & 430 \\
\hline type of cement & {$[-]$} & CEM I 42.5 N (sd) (OPC) \\
\hline w/c-ratio & {$[-]$} & 0.42 & 0.42 \\
\hline consistency & {$[-]$} & stiff & stiff / soft \\
\hline air content & {$[$ Vol.-\%] } & $4.0-4.5$ & $5.0-5.5$ \\
\hline max. grain size & {$[\mathrm{mm}]$} & 22 & 8 \\
\hline Rhine Sand 0/2 mm & {$[$ Vol.-\%] } & 28 & 30 \\
\hline Basalt grit 2/8 mm & {$[$ Vol.-\%] } & 15 & 70 \\
\hline Basalt grit 8/16 mm & {$[$ Vol.-\%] } & 27 & - \\
\hline Basalt grit 16/22 mm & {$[$ Vol.-\%] } & 30 & - \\
\hline
\end{tabular}

The old concrete represented a characteristic baselayer-concrete with a maximum grain size of $22 \mathrm{~mm}$ (basalt grit) with a cement content of $360 \mathrm{~kg} / \mathrm{m}^{3}$ and a w/c-ratio of 0.42 . For the concrete beam VB-7 a cement content of $380 \mathrm{~kg} / \mathrm{m}^{3}$ and a w/c-ratio of 0.33 were used. The mix designs of both concretes are displayed in Table 2 . The new concrete represented an exposed-aggregateconcrete (Table 2) with a maximum grain size of $8 \mathrm{~mm}$ (basalt grit) with a cement content of $430 \mathrm{~kg} / \mathrm{m}^{3}$ and a w/c-ratio of 0,42 . Both concretes contained an airentraining agent in the appropriate dosage. 


\subsection{Cyclic loading of large concrete beams and freeze thaw exposure}

At the age of 56 days (after production of the new concrete), the beams were stressed cyclically in 4-pointflexural-tests with up to 1.000 .000 load cycles. Therefore the multiple test-setup for simultaneous testing of six large format concrete beams was used (Figure 3).

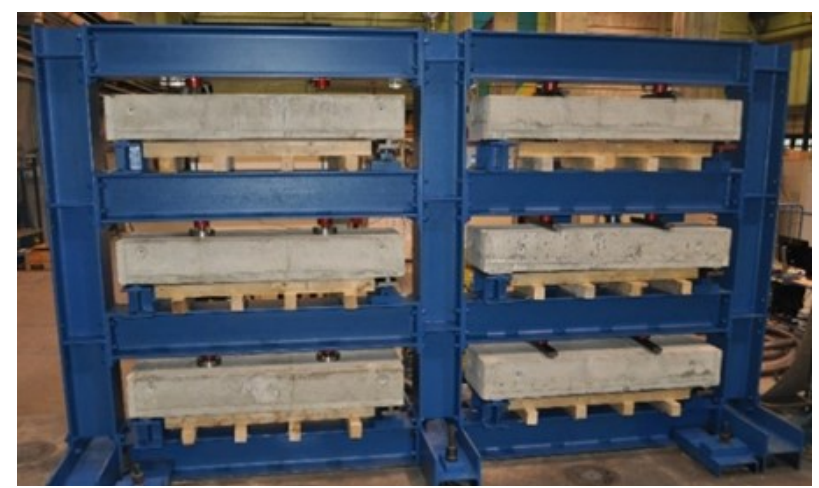

Fig. 3. Multiple test-setup for simultaneous cyclic testing of six large-format specimens

This setup is an in-house development of the Institute for Building Materials and was tested and used successfully in several research projects [8]. Herein, for the cyclic loading a stress level $\sigma / f_{\mathrm{ct}, \mathrm{fl}}=0.4$ was set $\left(\mathrm{f}_{\mathrm{ct}, \mathrm{fl}}\right.$ : 4.5 $\mathrm{MPa}$ ), because this value corresponds to the assumed stresses from hygric and thermal deformations as well as from traffic loads. The load range $\left(\sigma_{\max }-\sigma_{\min }\right)$ was defined by $1 \mathrm{MPa}$, corresponding to the flexural stresses caused by an 11.5-t-axle. The arrangement of the bearings and the load introduction points in the fourpoint-flexural-tests are shown in Figure 4. The distance between the load introductions is $80 \mathrm{~cm}$, the distance to the respective bearings $40 \mathrm{~cm}$. With a specimen length of $180 \mathrm{~cm}$, a supernatant beyond the bearing remains amounting to $10 \mathrm{~cm}$ on each side of the beam.

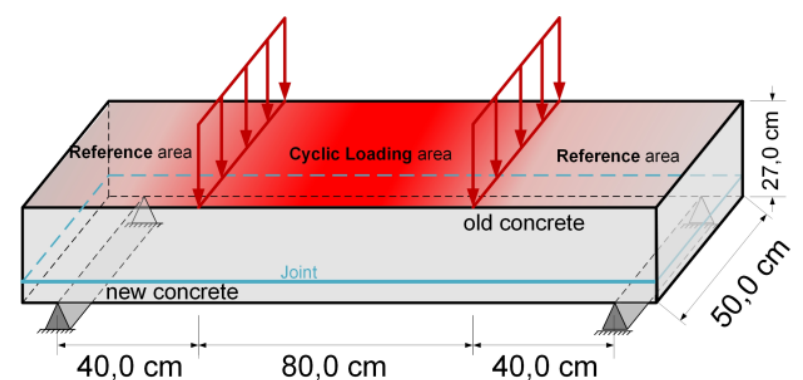

Fig. 4. Loading scheme in the 4-point-flexural-tests

Figure 5 shows an example of the loading scenario for the cyclic loading of large-scale specimens. Herein, the maximum load is initially applied under stroke control in order to avoid damage to the system in the event of a possible failure of the test specimens.

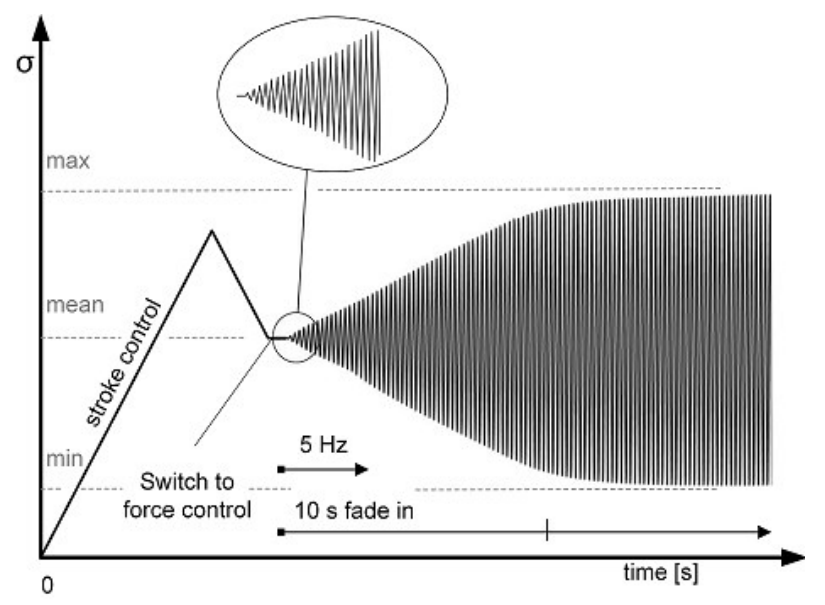

Fig. 5. Loading scenario

Subsequently, the load is reduced to medium load and switched to force control. When the cyclic load starts, the amplitude increases evenly over a period of time (max. 10 seconds) until the determined maximum load is reached. The continuous cyclic loading then takes place at the desired frequency. The maximum frequency with which the specimens can be loaded is at approx. 5 $\mathrm{Hz}$ depending on the level of the load. A higher frequency may possibly cause the test setup to natural oscillation.

In several research projects, the degradation of the structure or the loss of stiffness of conventional concretes for road constructions as a function of different numbers of load cycles was recorded. By ultrasonic measurements on the tensile stressed surface (tensile zone) of the specimens and the average relative dynamic modulus of elasticity derived from this, a decrease in stiffness with increasing load cycles could be detected (Figure 6, bottom).
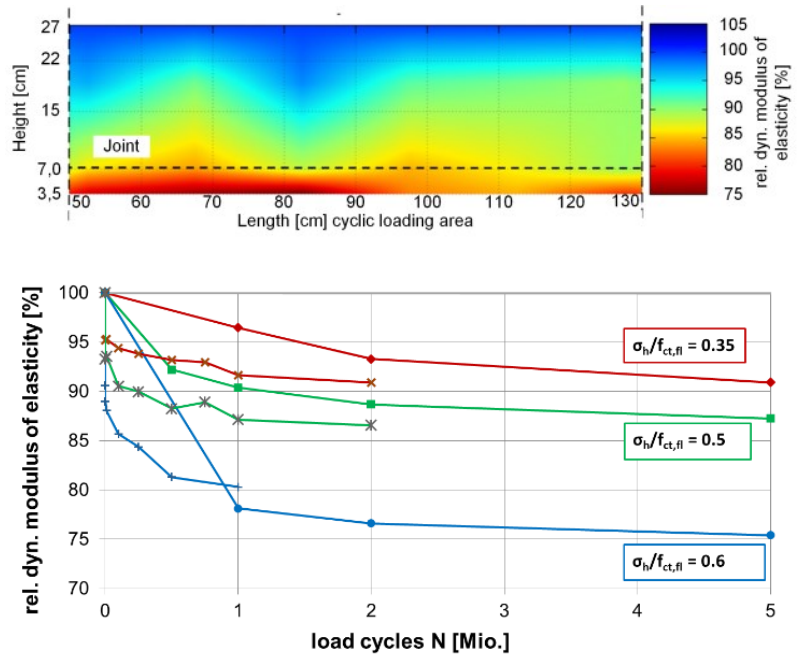

Fig. 6. Top: Visualization of the relative dynamic modulus of elasticity measured at the lateral surface of a two lift concrete specimen [9]. Bottom: Decrease of the rel. dyn. modulus of elasticity of beams after 1,2 and 5 million load cycles and at different stress-levels [10]

This decrease extends to the area of the joint $(7 \mathrm{~cm}$ new concrete) in a two lift concrete pavement, shown by 
the visualized ultrasonic measurement values of the lateral surface of a specimen (Figure 6, top).

Subsequent to the cyclic loading, drilled cores with a cross-section dimension of $d=100 \mathrm{~mm}$ and $\mathrm{d}=150 \mathrm{~mm}$ were taken from the unstressed reference area ("Reference") and the maximum stressed area ("Cyclic loading") (see Figure 4). After cyclic loading, some of the drilled cores taken from the maximum stressed area were additionally exposed to a freeze-thaw-attack based on a modified CDF-test regarding DIN CEN/TS 12390-9 [11] before the investigation of the bonding properties. This test included a capillary suction period of 7 days followed by 28 freeze-thaw-cycles. These specimens are further referred to as "Cyclic loading+ FT-attack".

\subsection{Investigations on the bonding properties}

The adhesive strength between old and new concrete was determined according to DIN EN 14488-4:2008-08 [12]. For this purpose, $40 \mathrm{~mm}$ thick steel stamps were attached to the front sides of the drilling cores. The tests were carried out on a servo-hydraulic testing machine (capacity $\pm 250 \mathrm{kN}$ ), whereas the tensile load was transmitted by eyebolts and hooks into the steel stamps. The testing speed amounted to $0.8 \mathrm{~mm} / \mathrm{min}$.

The adhesive shear strength was determined according to the shear test regarding to the German guideline TP Asphalt-StB - part 80 [13] (Figure 7). In this test setup, shear stress is applied to the bond area between the old and the new concrete in a defined level. Therefore, only the old concrete is fixated in the test setup and the stress is applied perpendicular to the drilled core, as close as possible to the bond area. The testing speed amounted to $0.6 \mathrm{~mm} / \mathrm{min}$.

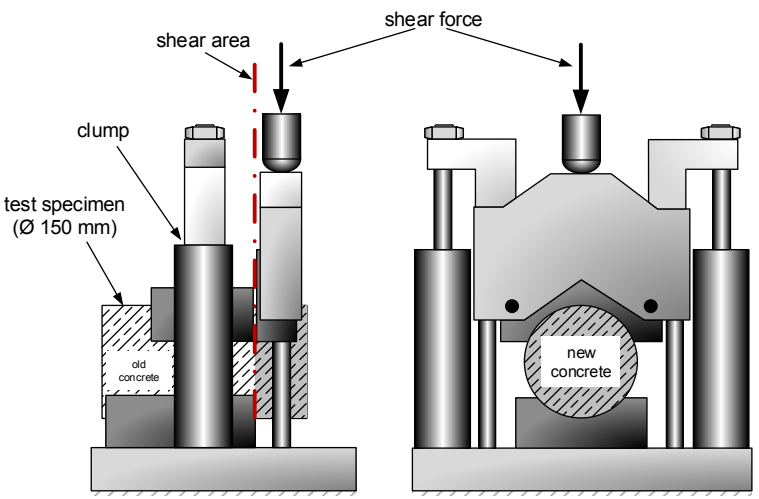

Fig. 7. Test setup for shear test according to the German guideline TP Asphalt-StB - part 80 [13]

\section{Results}

Within the experimental investigations it was shown that the moisture condition of the bond area at the time of application of the new concrete as well as the use of an adhesion primer are only of minor importance.

In the first case, only the moisture condition of the structural joint (old concrete) varied between moist condition for VB-1 and dry condition for VB-2. As can be seen from Figure 8 (top), concrete beam VB-2 attained up to $19 \%$ higher average adhesive strength compared to VB-1. A difference between the test specimens "Reference” and „Cyclic loading" was not observed at this point. The testing after an additional freeze/thaw-attack („Cyclic loading + FT-attack“) resulted in almost identical average adhesive strengths of 2.22 MPa for VB-1 and 2.28 MPa for VB-2. Within the adhesive shear test, VB-2 (dry conditions) showed up to $11 \%$ higher average adhesive shear strength in comparison to VB-1 (Figure 8, bottom). For the latter specimens „Cyclic loading“ showed approximately $6 \%$ less adhesive shear strength than the corresponding "Reference". For VB-2 the adhesive shear strength decreased only by approximately $2 \%$. The specimens „Cyclic loading + FT-attack“ attained almost identical adhesive shear strengths with $5.58 \mathrm{MPa}$ (VB-1) and $5.50 \mathrm{MPa}$ (VB-2). Concluding, a dry condition of the structural joint only showed an improvement of the bonding properties of the specimens „Reference“ and „Cyclic loading“.
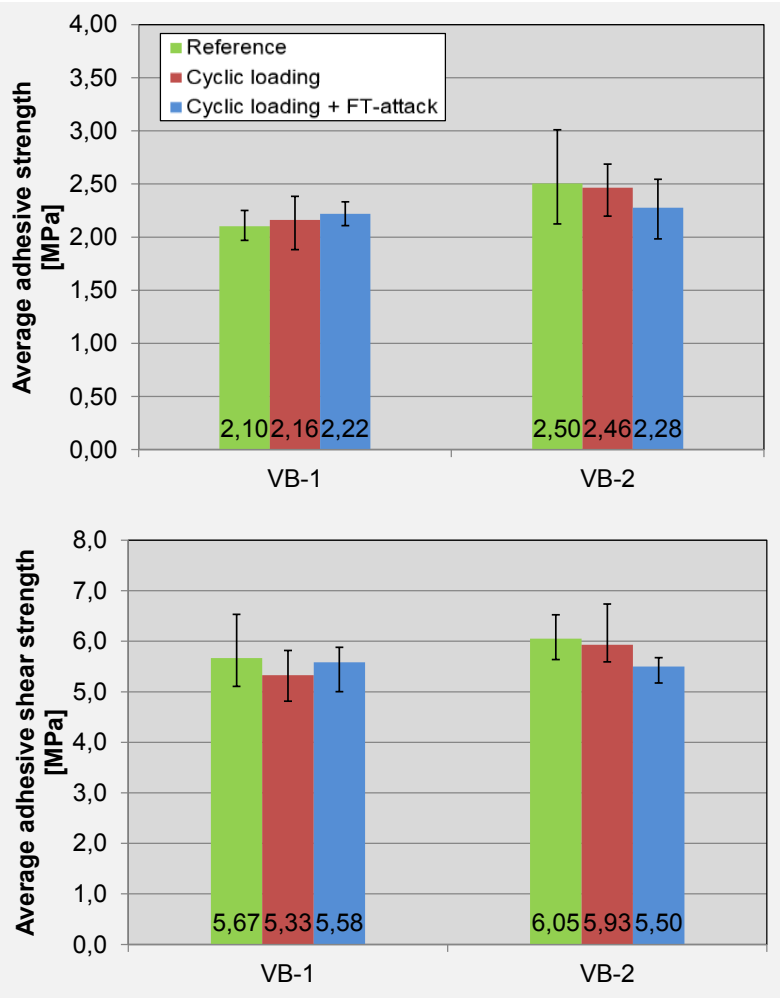

Fig. 8. Average adhesive strength (top) and adhesive shear strength (bottom) of VB-1 and VB-2 (without adhesive primer, without SRA, soft consistency; VB-1: moist and VB-2: dry condition)

Figure 9 displays the results of the bonding strength tests of concrete beams $\mathrm{H}-2$ und $\mathrm{H}-3$, which were produced using an adhesive primer before application of the new concrete. The new concrete was produced with a stiff consistency and with addition of SRA. The structural joint of $\mathrm{H}-2$ was adjusted to a moist condition and $\mathrm{H}-3$ to a dry condition. 

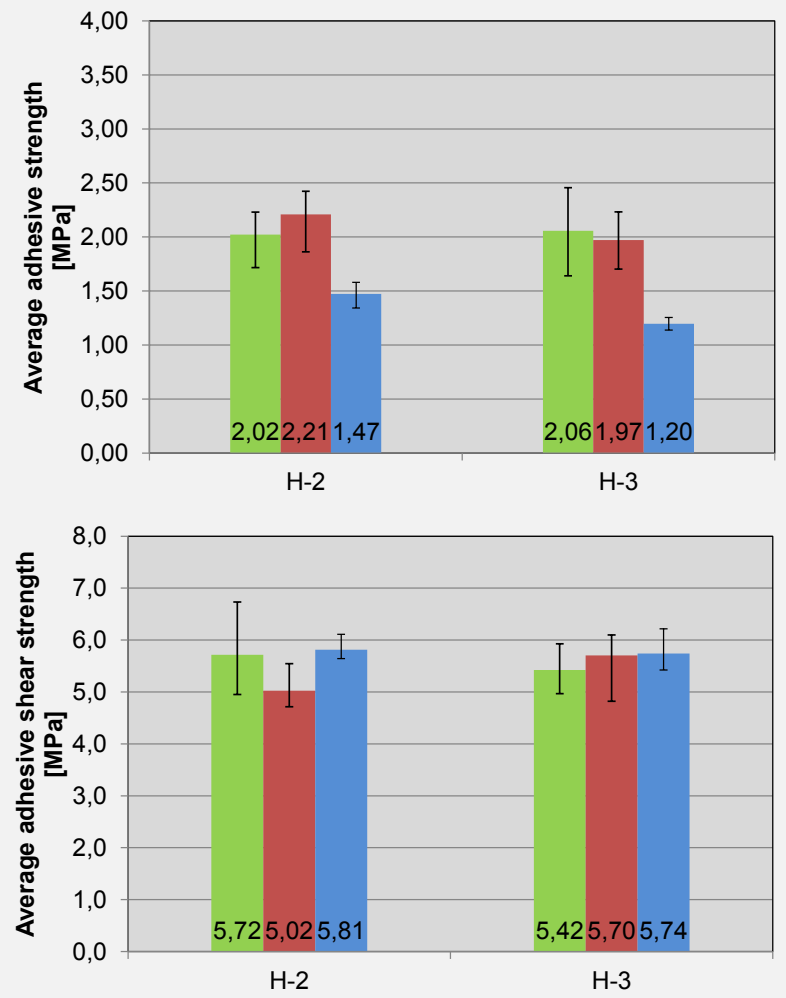

Fig. 9. Average adhesive strength (top) and adhesive shear strength (bottom) of $\mathrm{H}-2$ and $\mathrm{H}-3$ (with adhesive primer, stiff consistency, New Concrete with SRA; H-2: moist, H-3: dry condition)

As shown in Figure 9 (top), the specimens „Reference“ revealed almost the same adhesive strength with $2.02 \mathrm{MPa}$ for $\mathrm{H}-2$ and $2.06 \mathrm{MPa}$ for $\mathrm{H}-3$. The specimens "Cyclic loading" and "Cyclic loading + FTattack" of H-2 (moist condition) achieved up to $22 \%$ higher average adhesive strengths compared to H-3. Compared to the corresponding reference specimens, the average adhesive strength of the "Cyclic loading + FTattack" specimens decreased significantly by about $27 \%$ for $\mathrm{H}-2$ and about $42 \%$ for $\mathrm{H}-3$. In contrast to the previous fracture patterns, the specimens "Cyclic loading + FT-attack" fractured entirely in the new concrete. Concrete beams, which were produced using an adhesive primer, new concrete with a stiff consistency and using a shrinkage reducing agent, reached higher adhesive strengths on a structural joint with a moist surface condition during the application of the top layer. The results of the adhesive shear strength tests for $\mathrm{H}-2$ and H-3 are given in Figure 9 (bottom). Therefore, no clear correlation between the average adhesive shear strength and the moist condition of the structural joint (old concrete) was determined. For example, the reference specimens of $\mathrm{H}-2$ showed an up to $5 \%$ higher strength $(5.72 \mathrm{MPa})$ in comparison to $\mathrm{H}-3$ (5.42 MPa). With regard to the specimens „Cyclic loading“, the adhesive shear strength of $\mathrm{H}-2$ decreased to $5.02 \mathrm{MPa}$ whereas for $\mathrm{H}-3$ it showed an increase to $5.70 \mathrm{MPa}$ in relation to the corresponding reference. The specimens ,Cyclic loading + FT-attack" attained almost identical adhesive shear strengths with 5.81 $\mathrm{MPa}(\mathrm{H}-2)$ and 5.74 $\mathrm{MPa}(\mathrm{H}-3)$
Figure 10 shows the influence of the exposure time of adhesive primer on the bonding properties by means of concrete beams H-2 und H-5.
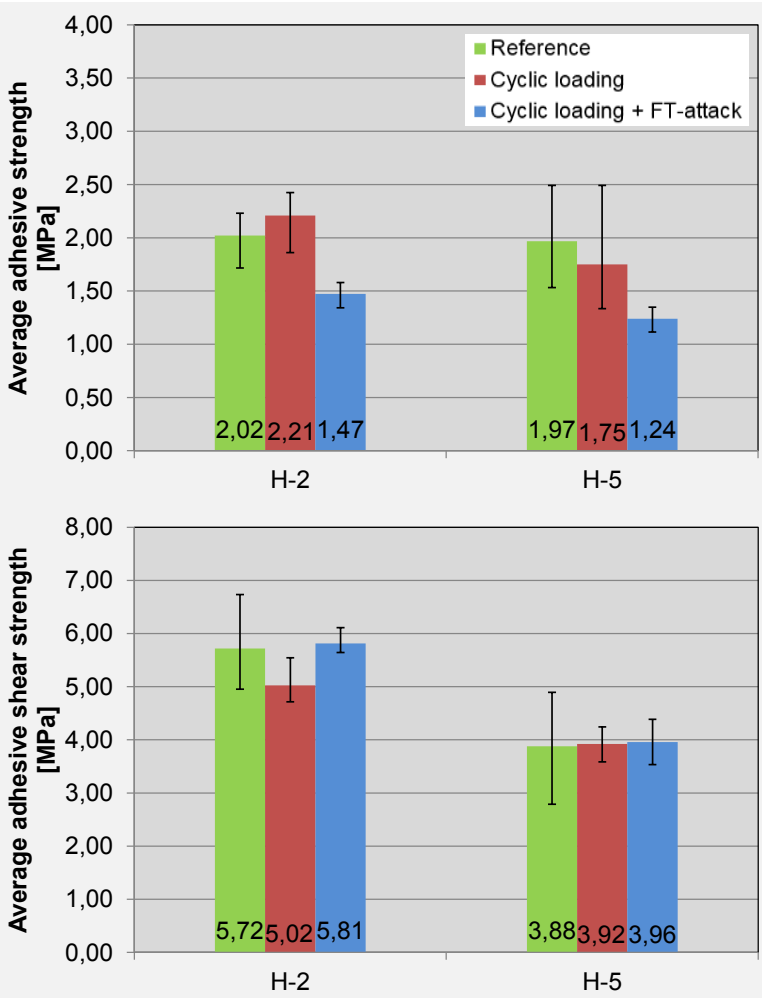

Fig. 10. Average adhesive strength (top) and adhesive shear strength (bottom) of H-2 and H-5 (moist condition of structural joint, new concrete with SRA, stiff consistency; H-2: exposure time: $0.5 \mathrm{~h}$ and $\mathrm{H}-5$ : exposure time: $2 \mathrm{~h}$ )

In both cases the adhesive primer was applied on the structural joint that was moistened. However, the exposure time of the adhesive primer amounted to 30 min. for H-2 and approx. $120 \mathrm{~min}$. for H-5. As the results indicate, the average adhesive strength of the reference specimens with $2.02 \mathrm{MPa}$ and $1.97 \mathrm{MPa}$ were almost identical. For the specimens „Cyclic loading“ an average adhesive strength of $2.21 \mathrm{MPa}$ was determined for H-2. H-5 showed a lower adhesive strength $(1.75 \mathrm{MPa})$. The additional freeze/thaw-attack led to a decrease of the average adhesive strength by about $33 \%$ (to $1.47 \mathrm{MPa}$ ) respectively by about $29 \%$ (to $1.24 \mathrm{MPa}$ ). As previously stated, the test specimens „Cyclic loading + FT-attack" fractured entirely in the new concrete, whereas the specimens "Reference" and "Cyclic loading" fractured in the old concrete as well as in the bond area. A possible influence of the exposure time of the adhesive primer became apparent within the results of the adhesive shear strength tests. In comparison to $\mathrm{H}-2$, the extended exposure time of 2 hours led to a significant decrease of the adhesive shear strength for $\mathrm{H}-5$ by up to $32 \%$ in comparison to $\mathrm{H}-2$. The cyclic loading as well as the cyclic loading and the freezethaw-attack showed no significant influence on the average adhesive shear strength. 
Using a new concrete with a soft consistency in combination with a higher compressive strength of the old concrete, there was a positive effect on the bond behaviour. Figure 11 shows the results of the bonding properties of VB-3 and VB-7, which differ in the compressive strength of the old concrete, with approx. $85 \mathrm{MPa}$ for VB-7 and approx. $62 \mathrm{MPa}$ for VB-3.
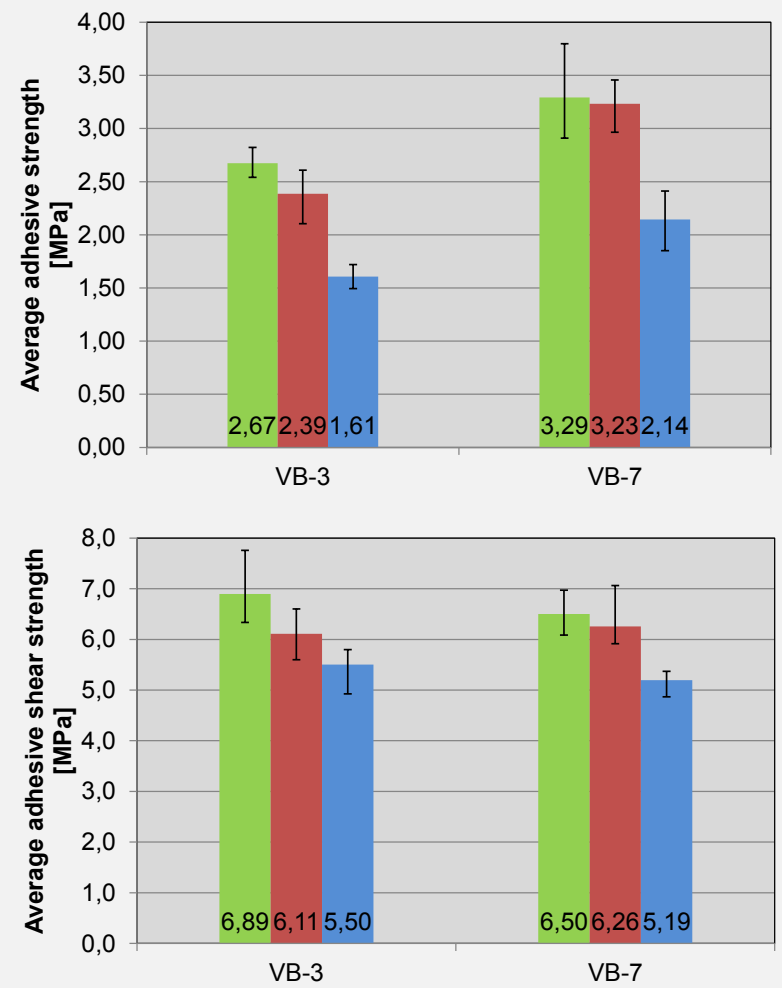

Fig. 11. Average adhesive strength (top) and adhesive shear strength (bottom) of VB-3 and VB-7 (moist condition, without adhesive primer, new concrete with SRA, soft consistency)

The results of the adhesive strength tests show that VB-7 attained up to $35 \%$ higher adhesive strength compared to VB-3. Furthermore, a higher decrease of the adhesive strength after cyclic loading and after cyclic loading and freeze/thaw-attack was determined for VB3. For example, the adhesive strength of the specimens „Cyclic loading“ decreased by about $11 \%$ and „Cyclic loading + FT-attack" by about $40 \%$ with respect to the reference. The results of the adhesive shear strength test (Figure 11, bottom) indicate that - contrary to the expectations - the average adhesive shear strength of VB-3 was up to $6 \%$ higher $(6.89 \mathrm{MPa})$ than of VB-7 $(6.50 \mathrm{MPa})$ and the decrease in adhesive shear strength due to cyclic loading and freeze-thaw attack is comparable. Based on this, a positive influence of the compressive strength of the old concrete on the adhesive shear strength could not be certainty determined.

During the production of the new concrete with shrinkage reducing agents (SRA), it was shown that the air content in fresh concrete could not be set unerringly. The air-void-parameters in hardened concrete could partially not be fulfilled. The use of SRA in concrete pavements needs further investigation to detect the exact boundary conditions for a robust concrete production.

\section{Application in practise}

The construction process of new concrete overlays for concrete pavements can be divided into the following stages. First of all, the existing road surface is milled (Figure 12). Therefore, only the damaged concrete is removed, which requires as a prerequisite a thoroughly status detection of the present pavement.

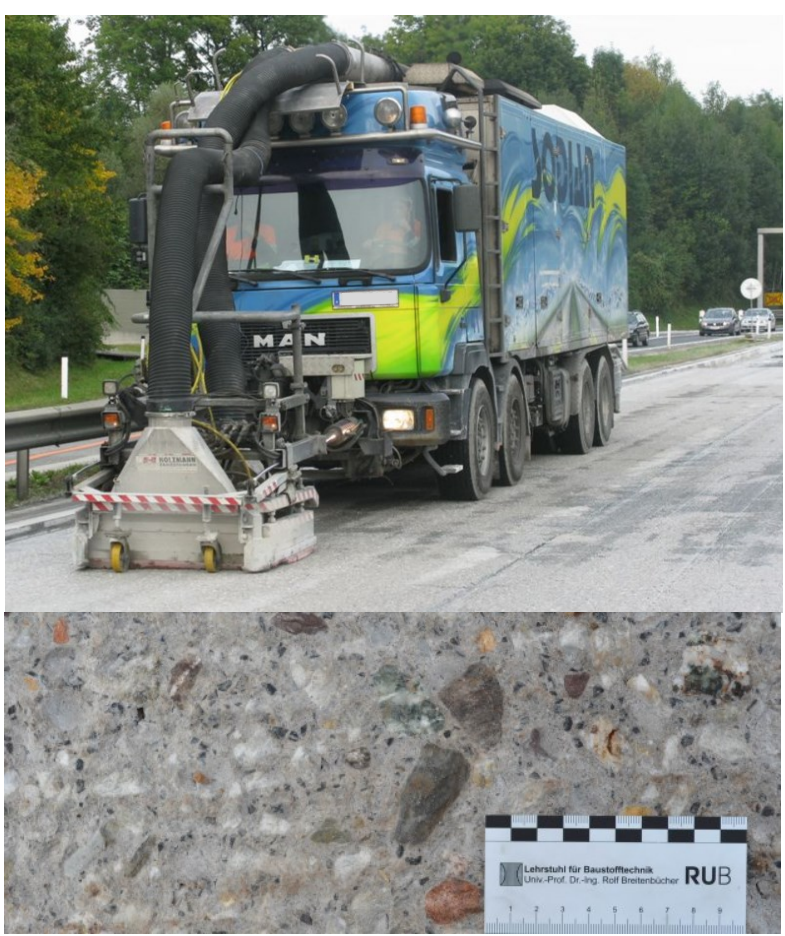

Fig. 12. Milling of an old concrete (top) (Source: STRABAG) and detail of a milled concrete surface (bottom)

Subsequently, after the treating of the surface with high-pressure water jets to remove the loose particles, the new concrete can be applied. In general, for the application of the concrete overlay typical road pavers can be used (Figure 13).

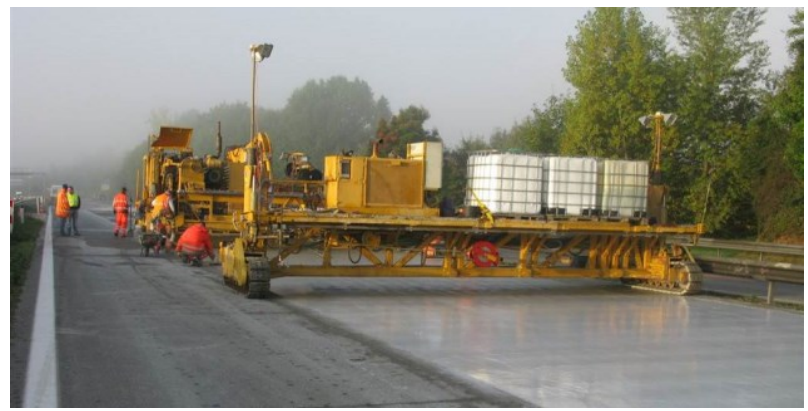

Fig. 13. Applying of the concrete overlay with a road paver (Source: STRABAG)

For curing of the concrete surface conventionally curing agents are used, in the case of exposed aggregates concrete a surface retarder is used. In Figure 14, a young concrete overlay next to the milled concrete surface is shown with a freshly cut joint, located above the separation crack. Next to this, a drilling core of such a concrete overlay of concrete pavements is displayed. 


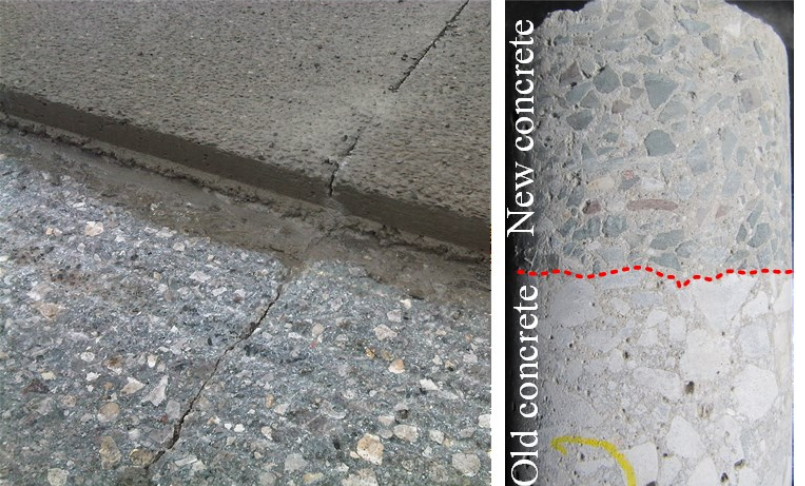

Fig. 14. Left: Milled old concrete and applied concrete overlay; Right: Drilling core of a bonded concrete overlay on concrete pavement (Source: STRABAG)

By now, the maintenance of deteriorated concrete pavements with jointed concrete overlays has successfully been realised on highways in Austria. As an example, bonded overlays were applied on A14 Rheintal motorway as well as A1 motorway at Salzburg. In the last 8 to 9 years since the completion of the maintenance, no damage has been detected up to the present time [14]. In contrast, jointless concrete overlays are subject of current investigations at the Institute of Building Materials, using carbon-reinforcement to bridge separation cracks in the old concrete and to avoid reflection cracks in the upper layer.

\section{Conclusion}

In this paper, relevant investigations on bonded systems produced with old concrete and a thin-layered new concrete were conducted. Herein, a number of parameters were varied including the moisture condition of the structural joint (old concrete), the application of adhesion primer, the consistency of new concrete etc. The bonding properties between the concrete layers were determined by the adhesive strength and the adhesive shear strength on drilling cores.

On the basis of these investigations the pre-treatment of the structural joint and special measures during the application of the thin-layered new concrete for concrete pavements can be defined in order to ensure a durable bond between old and new concrete.

The experimental investigations have shown, that the moisture condition of the structural joint (between old and new concrete) does not play a significant role for the bonding behaviour. Furthermore, the application of an adhesive primer is only useful when the maximum exposure time can be certainly ensured. In this case, a moist or dry condition of the surface of the old concrete is not relevant. An extended exposure time of the adhesive primer decreased the bonding properties significantly. A soft consistency of the new concrete combined with a high compressive strength of the old concrete has a positive effect on the bond behaviour.

The authors are grateful to the Federal Ministry of Transport and Digital Infrastructure and the Federal Highway Research Institute (Germany) for their financial support of this research project.

\section{References}

1. Harrington, D. Guide to Concrete Overlays Sustainable Solutions for Resurfacing and Rehabilitating Existing Pavements. Second Edition, September 2008. National Concrete Pavement Technology Center, Aimes, Iowa, U.S.A.

2. Eid, J. "Theoretische und experimentelle Untersuchungen dünner Betondecken auf Asphalt (Whitetopping)". 2012. Dissertation

3. Eid, J. und Freudenstein, S. "Whitetopping - eine Versuchsstrecke. Betontechnologie, Bauausführung und Bewertung der Ergebnisse". Beton, Jg.: 62, Nr.11, 2012, Seite 432-438

4. Riffel, S. "Eine zukunftsfähige Sanierungsmethode mit Beton: Whitetopping". Fachbeitrag Straßenbau 06/2009

5. Schmerbeck, R., Riffel, S.; Wolf, T. (2010) "Whitetopping - Erprobungsstrecke im Zuge einer Erneuerung". Bauportal, Seite 467-471, Jg.: 122, Nr.8

6. Werner, R. (2005) "Whitetopping - die weiße Alternative zur Sanierung von Asphaltbelägen (4/2005)".

7. TL Beton-StB, Technische Lieferbedingungen für Baustoffe und Baustoffgemische für Tragschichten mit hydraulischen Bindemitteln und Fahrbahndecken aus Beton, Forschungsgesellschaft für Straßen- und Verkehrswesen, Ausgabe 2007

8. Przondziono, R., Schulte-Schrepping, C., Breitenbücher, R.; Innovativer Mehrfachprüfstand zur zyklischen Beanspruchung großformatiger Betonprobekörper. Beton- und Stahlbetonbau 113 (2018), S. 48-57.

9. Müller, M., Ludwig, H.-M., Schulte-Schrepping, C., Breitenbücher, R. Dauerhafte Betonfahrbahndecken durch Verwendung unterschiedlicher Bindemittel in Ober- und Unterbeton. Beton- und Stahlbetonbau 112 (2017), S 219-227.

10. Przondziono, R.; Timothy, J.J.; Weise, F.; Krütt, E.; Breitenbücher, R.; Meschke, G.; Hofmann, M. Degradation in concrete structures due to cyclic loading and its effect on mass transport processes experiments and modeling. Structural Concrete (2017), 18, S. 519-527.

11. DIN CEN/TS 12390-9, Freeze-thaw resistance Scaling; 2006

12. DIN EN 14488-4, Testing sprayed concrete -Part 4: Bond strength of cores by direct tension; 2008

13. TP Asphalt-StB, Technische Prüfvorschriften für Asphalt -Teil 80: Abscherversuch, Ausgabe 2007, FGSV, Köln

14. NÖBI - Neue österreichische BetondeckenInstandsetzungsmethode DI Stefan Spalt, ASFINAG Baumanagement $\mathrm{GmbH}, \quad$ Österreichischer Betonstraßentag 2012, Betonstraßenbau: heute und morgen 